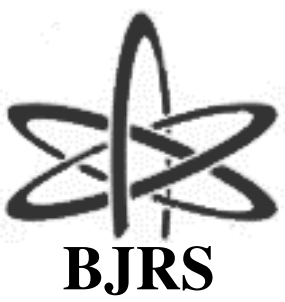

BRAZILIAN JOURNAL

$\mathrm{OF}$

RADIATION SCIENCES

03-1A (2015) 01-06

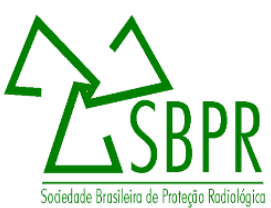

\title{
Determination of the tube voltage from clinic mammographic system using two types of detectors
}

\author{
J. S. Barreira $;$, V. Vivolo ${ }^{\mathrm{a}}$ \\ ${ }^{a}$ Gerência de Metrologia das Radiações/Laboratório de Calibração de Instrumentos, Instituto de Pesquisas \\ Energéticas e Nucleares, 05508-000, São Paulo-SP, Brasil \\ jacsales@usp.br
}

\begin{abstract}
The use of $\mathrm{X}$ rays for diagnostic radiology is very common and important to Medicine, including mammographic diagnosis focusing decreasing of the doses applied to the patients and preserving high quality of the diagnostic image. A quality control program of the irradiation systems it is necessary to control periodically the performance of the X-ray systems applied in that diagnosis in order to obtain the best results in that diagnosis. The verification of the beam characteristics is made by using standard dosimetric procedures which include the determination of the kilovoltage and the kerma rates for the different radiation qualities applied in the diagnosis. The Instruments Calibration Laboratory (LCI) of IPEN perform calibration in dosemeters used in radiation dosimetry (in diagnostic radiology) for many years and are improving their methodology to attend the actual demand of that equipments used in quality control of that X-radiation systems. The objective of that paper were the measurements of $\mathrm{kVp}$ and air kerma produced for one mammographic system of LCI, Model VMI - Graphmammo AF (Philips) using two different measurements systems from PTW (Diavolt) and Radcal ( $\mathrm{kVp}$ meter) that procedure is just to determine the stability of that system that is used to perform diagnosis in mammography level. The results obtained with the two systems utilized shows good agreement. That measurement can be applied at a routine quality control program of that X-ray system.
\end{abstract}

Keywords: Dosimetry; X-ray; Mammography 


\section{INTRODUCTION}

Breast cancer accounts for nearly $25 \%$ of all cases and is the most common type among women in the world. Estimates for 2014 indicate 57,000 new cases of breast cancer in Brazil, the third highest incidence, behind melanoma and prostate cancer.

The World Health Organization (WHO) estimates 27 million new cancer cases for 2030 worldwide, and 17 million deaths from the disease. Developing countries will be most affected, including Brazil. [1]

Given this scenario, it becomes essential mammography in screening and detection of breast cancer. But to obtain a suitable image, it is necessary that the X-ray emitter equipment is properly calibrated.

The objective of that paper were the measurements of $\mathrm{kVp}$ and air kerma produced for one mammographic system of LCI, Model VMI - Graphmammo AF (Philips) using two different measurements systems from PTW (Diavolt) and Radcal ( $\mathrm{kVp}$ meter) that procedure is just to determine the stability of that system that is used to perform diagnosis in mammography level. That measurement can be applied at a routine quality control program of that X-ray system.

\section{MATERIALS AND METHODS}

In this study were used the VMI Graph Mammo AF Phillips, who operates in the range 20 to 35 kilovolts $(\mathrm{kV})$, has target of Molybdenum (Mo) and inherent filter Rhodium (Rh) and Molybdenum.

To perform the measurements, were used PTW Universal All-in-one QC Meter T43014 (noninvasive meter). This machine performs multiple measurements in a single exposure, like the dose in $\mathrm{mGy}$, the time of exposure in $\mathrm{ms}$, the mean $\mathrm{kVp}$ and the maximum $\mathrm{kVp}$.

For reproducibility test of the tube voltage, were used the Accu meter Radcal kV model 4082 coupled to the sensor with high sensitivity Radcal Accu kV 22-40 kV, Model 40x5 - Mo. The equipment was kindly provided by Physics Institute (São Paulo University). 
Tension $(\mathrm{kV})$ used in typical mammography beams intervals were selected: 25, 28, 30 and 35 $\mathrm{kV}$. The objective was to verify if the measured $\mathrm{kV}$ was in agreement with the nominal $\mathrm{kV}$ mammography and its reproducibility.

The meter (Radcal Accu kV or PTW Diavolt) was positioned in the center of the sensor support breast, $4 \mathrm{~cm}$ from the edge thereof, and third exposures with intervals of each voltage $(\mathrm{kV})$ for mammography mentioned above were performed.

The values obtained were compared to verify the reproducibility of measurements/ exhibitions. Then, the average value of the three was calculated and displays the obtained value was compared with the nominal $\mathrm{kV}$ for obtaining accurately the tube voltage.

For determination of the dose, were conducted measurements with $28 \mathrm{kV}$ and mAs varied, with PTW Diavolt, centered at the point of incidence radioactive beam. The meter Radccal Accu kV measure only tension, not dose, thus no comparison between the results of two equipments.

\section{RESULTS AND DISCUSSION}

The PTW Diavolt acquired the best reproducibility in 30 and $35 \mathrm{kV}$, the same reproducibility than meter Radcal Accu kV for $28 \mathrm{kV}$. Only in $25 \mathrm{kV}$, the variation measured with PTW Diavolt is larger than variation acquired by Radcal Accu $\mathrm{kV}$ (table 1).

It can be seen that the reproducibility is within the IEC 61676 standard [2], IAEA / ARCAL XLIX [3], where the variation between measurements on the same $\mathrm{kV}$ can not be greater than \pm $2 \%$.

Table 1: Reproducibility of tube voltage with Radcal Accu kV and PTW Diavolt:

\begin{tabular}{ccc}
\hline & \multicolumn{2}{c}{ Variation with two detectors } \\
\cline { 2 - 3 } Nominal tension & Radcal Accu kV & PTW Diavolt \\
\hline $\mathbf{2 5}$ & $\pm 0,02 \%$ & $\pm 0,04 \%$ \\
$\mathbf{2 8}$ & $\pm 0,02 \%$ & $\pm 0,02 \%$ \\
$\mathbf{3 0}$ & $\pm 0,01 \%$ & 0 \\
$\mathbf{3 5}$ & $\pm 0,01 \%$ & 0 \\
\hline
\end{tabular}

Reproducibility test of the tube voltage with the intervals of the mammography 
The PTW Diavolt acquired the best reproducibility in 30 and $35 \mathrm{kV}$, the same reproducibility than meter Radcal Accu kV for $28 \mathrm{kV}$. Only in $25 \mathrm{kV}$, the variation measured with PTW Diavolt is larger than variation acquired by Radcal Accu $\mathrm{kV}$.

It can be seen that the reproducibility is within the IEC 61676 standard [2], IAEA / ARCAL XLIX [3], where the variation between measurements on the same $\mathrm{kV}$ can not be greater than \pm $2 \%$.

Table 2 lists the results that were obtained in the accuracy of the test tube voltage with Radcal Accu kV:

Table 2: Accuracy of the test tube voltage with Radcal Accu kV:

\begin{tabular}{ccc}
\hline & \multicolumn{2}{c}{ Tension measured with Radcal Accu kV } \\
\cline { 2 - 3 } Nominal tension & Measured tension & Variation \\
\hline $\mathbf{2 5}$ & 24,9 & $\pm 0,01 \%$ \\
$\mathbf{2 8}$ & 28 & 0 \\
$\mathbf{3 0}$ & 29,9 & $\pm 0,01 \%$ \\
$\mathbf{3 5}$ & 34,7 & $\pm 0,08 \%$ \\
\hline
\end{tabular}

Values obtained in the accuracy test tube voltage

Table 3 lists the results that were obtained in the accuracy of the test tube voltage with PTW Diavolt:

Table 3: Accuracy of the test tube voltage with PTW Diavolt:

\begin{tabular}{ccc}
\hline & \multicolumn{2}{c}{ Tension measured with PTW Diavolt } \\
\cline { 2 - 3 } Nominal tension & Measured tension & Variation \\
\hline $\mathbf{2 5}$ & 25,5 & $\pm 0,1 \%$ \\
$\mathbf{2 8}$ & 28,1 & $\pm 0,03 \%$ \\
$\mathbf{3 0}$ & 30,2 & $\pm 0,06 \%$ \\
$\mathbf{3 5}$ & 35,5 & $\pm 0,1 \%$ \\
\hline
\end{tabular}

Values obtained in the accuracy test tube voltage

It appears that the accuracy of the tube voltage is in accordance with IEC 61676, IAEA / ARCAL XLIX where the variation between the measured and nominal $\mathrm{kV}$ can not be greater than $\pm 5 \%$. In this test, the meter Radcal Accu $\mathrm{kV}$ was more specific than PTW Diavolt. 
Table 4 presents the maximum average $k V p$ and $k V p$ with PTW Diavolt obtained for each strain selected in mammography. Radcal Accu $\mathrm{kV}$ not measured this tensions, so there was no comparison between the results.

Table 4: Maximum and mean kVp measured with PTW Diavolt:

\begin{tabular}{ccc}
\hline & \multicolumn{2}{c}{$\mathbf{k V p}$ measured with PTW Diavolt } \\
\cline { 2 - 3 } Nominal tension & Maximum $\mathbf{k V p}$ & Mean $\mathbf{k V p}$ \\
\hline $\mathbf{2 5}$ & 25,6 & 25,5 \\
$\mathbf{2 8}$ & 28,3 & 28,1 \\
$\mathbf{3 0}$ & 30,3 & 30,2 \\
$\mathbf{3 5}$ & 35,6 & 35,5 \\
\hline
\end{tabular}

Values of maximum and mean $k V p$ in the range of voltage $(k V)$ to mammography, used meter PTW Diavolt

According to ANVISA's 2005 manual [4], the air Kerma rate for a given kV and mAs can not vary more than $10 \%$ in 4 consecutive exposures. Table 5 shows the results.

Table 5: Kerma rate measured with PTW Diavolt

\begin{tabular}{ccc}
\hline & \multicolumn{2}{c}{ Kerma rate } \\
\cline { 2 - 3 } $\begin{array}{c}\text { Current-time production } \\
\text { (mAs) }\end{array}$ & Kerma (mGy) & Variation \\
\hline $\mathbf{2 0}$ & & $\pm 0,9 \%$ \\
$\mathbf{5 0}$ & 5,2 & $\pm 0,2 \%$ \\
$\mathbf{1 0 0}$ & 11,39 & $\pm 0,1 \%$ \\
$\mathbf{2 0 0}$ & 22,82 & 0 \\
\hline
\end{tabular}

Variation of air Kerma at different mAs did not exceed 10\%. Result is within the norm of ANVISA (2005)

\section{CONCLUSIONS}

The measurements of $\mathrm{kVp}$ and air kerma produced by mammographic system of LCI, Model VMI - Graphmammo AF (Philips) using two different measurements systems from PTW (Diavolt) and Radcal (kVp meter) shows the stability of that system. The results obtained with 
the two equipments utilized shows good agreement. That measurement can be applied at a routine quality control program of that X-ray system.

\section{REFERENCES}

1. INCA - Instituto Nacional Do Câncer. Estimativa I 2012 - Incidência de Câncer no Brasil. Rio de Janeiro, RJ - 2011.

2. IEC - International Electrotechnical Commission. Medical electrical equipment Dosimetric instruments used for non-invasive measurement of $X$-ray tube voltage in diagnostic radiology. IEC 61676, Geneva, 2002.

3. IAEA / ARCAL XLIX - International Atomic Energy Agency / Acuerdo de Cooperación Regional para la Promoción de la Ciencia Nuclear y Tecnología em América Latina y el Caribe. Protocolos de Control de Calidad en Radiodiagnostico. - 2001.

4. ANVISA - Agência Nacional De Vigilância Sanitária. Radiodiagnóstico Médico: Desempenho de Equipamentos e Segurança. Brasília: Ministério da Saúde, 2005. 